\title{
GNOSTICISMO, DERECHO Y LEY NATURAL
}

\author{
Gnosticism, Law and Natural Law \\ Gnosticismo, Legge e legge naturale
}

Félix Adolfo Lamas ${ }^{1}$

Para citar este artículo:

Lamas, F.A. (2020). "Gnosticismo, Derecho y ley natural”.

Prudentia Iuris, N. Aniversario, pp. 31-46.

DOI: https://doi.org/10.46553/prudentia.aniversario.2020.pp.31-46

Resumen: El gnosticismo afecta al pensamiento jurídico mediante tópicos que tienen en común negar la realidad concreta de las cosas del Derecho. En este trabajo, el autor caracteriza en general las corrientes gnósticas y atiende en especial a tres tópicos que tendrían como función teórica sustituir la doctrina clásica y realista de la ley natural: el consenso, los llamados "Derechos Humanos" y la apelación ambigua a la "dignidad de la persona humana".

Palabras clave: Gnosticismo; Ley natural; Consenso; "Derechos Humanos"; "Analogía y dignidad de la persona".

Abstract: Gnosticism affects legal thought through topics that have in common denying the concrete reality of things in Law. In this work, the author generally characterizes the Gnostic currents and attends especially to three topics that would have as a theoretical function to replace the classic and realistic doctrine of natural law: consensus, the so-called "Human Rights" and the ambiguous appeal to the "Dignity of the human person".

1 Profesor Emérito de la Facultad de Derecho, Pontificia Universidad Católica Argentina. Director del Seminario de Filosofía y Teología orientadas al Derecho de la Pontificia Universidad Católica Argentina. Correo electrónico: felixlamas@uca.edu.ar. 
Keywords: Gnosticism; Natural Law; Consensus; "Human Rights"; "Analogy and dignity of the person".

Sommario: Lo gnosticismo influenza il pensiero giuridico attraverso argomenti che hanno in comune la negazione della realtà concreta delle cose del diritto. In questo testo, l'autore caratterizza in generale le correnti gnostiche e si occupa in particolare di tre temi che avrebbero come funzione teorica di sostituire la dottrina classica e realistica del diritto naturale: il consenso, i cosiddetti "Diritti Umani" e l'ambiguo appello al "Dignità della persona umana".

Parole chiave: Gnosticismo; Legge naturale; Consenso; "Diritti Umani”; "Analogia e dignità della persona".

\section{Introducción}

\section{1. ¿Qué es el gnosticismo?}

El gnosticismo es, desde hace varios siglos, la ideología dominante de la política, el Derecho y la Filosofía de la historia ${ }^{2}$. Se trata de un multiforme movimiento religioso, filosófico o simplemente cultural con una concepción global del mundo, del hombre, de la vida y de Dios que, como es lógico, tiene importantes proyecciones y consecuencias en el campo de la política y del Derecho.

Suelen agruparse con el nombre de gnosticismo ${ }^{3}$ diversas sectas y escuelas de pensamiento religioso herético de los primeros siglos de la era cristiana (entre el siglo II y el V), de origen cristiano o judío, que pretendían penetrar los misterios de Dios, del mundo, del demonio y del alma mediante la razón, asistida por una supuesta iluminación divina o demoníaca ${ }^{4}$. Más allá de sus fantasías míticas, pueden sintetizarse sus ideas principales, de interés filosófico, de la siguiente manera:

2 Eric Voegelin ha llamado la atención sobre el hecho de que el Gnosticismo es la ideología y el problema dominante de la política a partir de la Edad Moderna, pero que se gestó en la Edad Media [cfr. (2006). La nueva ciencia de la política. Una introducción. Buenos Aires. Katz, caps. IV y V].

3 El término proviene de la palabra griega gnosis (conocimiento).

4 Cfr. (1990). Los gnósticos (compilación). Intr., trad. y notas de José Montserrat Torrents. 2 tomos. Madrid. Gredos. 
a) Eran inmanentistas, es decir, no reconocían un principio trascendente del mundo, sino que la realidad mundanal tiene en ella misma su fundamento.

b) Eran también emanatistas, en la medida en que las supuestas divinidades y las cosas en general procedían de un principio (inmanente) por emanación, con fuertes influencias órfico-pitagóricas y neo-platónicas.

c) Negaban la realidad de esencias específicas, como la naturaleza humana y, por lo tanto, eran nominalistas, con todas sus consecuencias lógicas y metafísicas.

d) Profesaban un cierto evolucionismo redentor -selectivo- a través del conocimiento (gnosis), reservado a unos poco iniciados.

A estas características cabe agregar que el gnosticismo antiguo y medieval, y parte del moderno, se organizaba en sectas iniciáticas, con prácticas mágicas y teúrgicas. Para ellos, ciertas almas eran de origen divino y debían reintegrarse en esa fuente originaria. Todo el universo material era instrumento u obstáculo para esa reintegración en la divinidad.

Las fuentes del gnosticismo son muy antiguas y oscuras. Una de ellas es la tradición órfico-pitagórica. Son evidentes también algunos contactos teóricos con el heraclitismo, el estoicismo antiguo y el neoplatonismo ${ }^{5}$.

\section{Diversas corrientes gnósticas antiguas}

La familia gnóstica antigua es numerosa. Citemos, por ejemplo, el her$m^{m e t i s m o}{ }^{6}$, los "Oráculos Caldeos"7, el maniqueísmo ${ }^{8}$ y la Kábala.

La Kábala merece una consideración especial ${ }^{9}$. Me he de circunscribir aquí a la Kábala judía, herética respecto a la tradición abrahámico-mosaica.

5 Aunque Plotino polemizó duramente contra ellos (cfr. Enéade II, 9), de la descripción anterior se infieren semejanzas profundas, que se acentuaron en el caso de Porfirio y, sobre todo, de Jámblico y Proclo.

6 Hay muchas versiones del Corpus hermeticum, cuya autenticidad es dudosa y no me atrevo a avalar. 2008.

7 Tengo a la vista la edición italiana bilingüe editado por Angelo Tonelli, Milano, BUR,

8 Entiendo que la mejor fuente para conocer el pensamiento maniqueo son los Escritos antimaniqueos, de San Agustín de Hipona [(1993), Obras completas. Tomos XXX y XXXI. Madrid. BAC, en especial el "Contra Faustum"].

9 Merece citarse la obra de Meinvielle, J. (1994). De la cábala al progresismo. Buenos Aires. Epheta. 
Tiene en común con el gnosticismo el inmanentismo, el emanatismo de divinidades, las fuentes órfico-pitagóricas, el carácter iniciático y la apelación a una presunta tradición de una revelación primordial. Vinculadas con ella, en la Edad Media se verificaron prácticas ocultistas, teúrgicas y mágicas, la numerología, la alquimia y otras sectas iniciáticas. Para poner un ejemplo de la importancia cultural de este movimiento, conviene recordar que están de un modo u otro conectados con la Kábala, la alquimia y la magia los padres de la física matemática, como Grosseteste (1175-1253), Roger Bacon y Francis Bacon.

Para la Kábala, la realidad se reduce al pensamiento y éste a palabras y números. Se trata, por lo tanto, de un idealismo nominalista y matematicista. Pero el pensamiento de que se habla, sea el de la divinidad (o divinidades) o el humano, no es principalmente teórico (de puro conocimiento), sino más bien práctico. La palabra o el número se identifican con la realidad o esencia de las cosas, y su posesión asegura el dominio sobre ellas. Aquí tiene origen no sólo la magia sino también el ideal moderno y contemporáneo de dominio técnico-matemático del mundo, progresivamente extendido a la propia vida humana, la cultura y la política. Al hacerse dueño de las palabras y números secretos de las cosas, el hombre, de alguna manera, se adueña también de la divinidad y de su omnipotencia.

Se advierte, a partir de lo dicho, la radical sustitución de la tradición clásica de la ley natural. Lo que para la tradición clásica es el orden de la naturaleza, constituido por esencias sustanciales dotadas de una finalidad intrínseca y de una vocación trascendente, para el gnosticismo kabalístico es un sistema de fenómenos numéricos y de relaciones cuantitativas detrás de los cuales están el número y la palabra divinas, inmanentes al universo.

\section{El gnosticismo moderno y contemporáneo}

El gnosticismo moderno, que se extiende hasta hoy, tiene, como se ha visto, sus raíces en la Edad Media. Y, claro está, tiene las mismas características esenciales del antiguo y del medieval. Pero se distingue de aquéllos porque no pretende justificarse en la fe o la revelación divina, sino sólo en la razón humana.

En particular, el gnosticismo moderno y contemporáneo niega explícitamente todo orden natural, y sus grandes instrumentos noéticos son el nominalismo, el empirismo, el matematicismo, el positivismo y -hoy- la inteligencia artificial $^{10}$.

10 Son gnósticos, o afines al gnosticismo, entre otros muchos, Hobbes, Hume, Francis Bacon, Leibniz, Hegel, Comte, etc. 
En materia religiosa, el gnosticismo está en el corazón de la teosofía, la llamada New Age, el modernismo y el progresismo que se autodenominan católicos $^{11}$, y la variadísima gama de relativismos culturales. Incluso el ecologismo ha devenido una forma de sustitución de lo religioso.

\section{El gnosticismo jurídico-político y sus tópicos}

Tanto el concepto del Estado cuanto la ley natural, que es el fundamento racional de la legitimidad del régimen y de las relaciones mando-obediencia, guardan, según la tradición clásica, una relación esencial con Dios. Por esta razón, es acertada la perspectiva que adopta Eric Voegelin al centrar la atención en la relación entre el pensamiento del Estado y la política con el gnosticismo, más allá de las reservas que puedan suscitar su marco teórico y su metodología.

Para el pensamiento clásico, Dios es un absoluto trascendente, autor del orden cósmico y humano, al que gobierna mediante su sabiduría eterna. La ley natural no se identifica con Dios, sino que es participación de esa sabiduría eterna en la naturaleza de las cosas y en la razón humana. Hay, pues, fines naturales, que gobiernan el devenir temporal, y un fin trascendente supratemporal, que no se confunden. El Estado tiene un fin temporal, que le es rigurosamente connatural, y a su vez tiene una ordenación supratemporal que está más allá de su existencia. Y si bien -en palabras de Platón y Aristóteles- el fin último del hombre es participar en la medida que es posible a su naturaleza de la vida divina (en el caso del cristianismo, mediante la elevación de aquélla al orden sobrenatural por la gracia), dicho fin trascendente no se alcanza en el tiempo ni es cometido directo de la comunidad política.

De ahí que una concepción inmanentista del Absoluto implique la confusión del orden de la política con el orden divino y la desnaturalización del Estado. Si el Absoluto es inmanente al mundo y a la comunidad política, el resultado es el totalitarismo que, según las diversas corrientes de pensamiento, será un absolutismo político, social, cultural, científico, económico o materialista.

Los tópicos gnósticos contemporáneos son numerosos. En esta ocasión voy a considerar sólo tres, que tienen una inmediata atingencia con la doctrina de la ley natural y el Derecho.

11 El papa S. Pío X caracterizó magistralmente (y magisterialmente) el modernismo en la Encíclica Pascendi. 


\section{Ley natural y consenso}

\section{El problema del consenso y la ley natural}

El tema del consenso es antiguo. En cambio, el tema del consenso y la ley natural no lo es. Mirado en perspectiva histórica, es reciente y, como problema, se justifica para aquellas corrientes gnósticas que, pese a ser nominalistas y por lo tanto relativistas, con una fuerte dosis de escepticismo, pretenden de alguna manera recoger la idea de ley natural para usufructuar algo de su prestigio. Si en cambio se preguntara a la tradición clásica, desde Platón a la Escuela Española, y los que la continuamos, en qué relación está el consenso con la ley natural, la respuesta es muy clara y breve: desde el punto de vista esencial no hay relación; puede haber alguna relación accidental, por ejemplo, en cuanto a la formulación de la ley natural, pero en sí la validez de la ley natural y su conocimiento no depende del consenso. Esta sería la respuesta breve.

Pero hay un problema. Cicerón, que es una de las principales fuentes acerca del tema, usa la expresión consensus iuris en vinculación inmediata con el concepto de concordia. Él define al pueblo como una multitud unida por el consenso de Derecho (consensus iuris) y por intereses comunes. Esa idea de un querer intereses comunes es la idea clásica de concordia (homónoia) para Aristóteles. En otro fragmento, que san Agustín cita en la Carta 38, Cicerón expresamente habla de concordia. Esta aproximación conceptual y semántica de consenso y concordia no se limita a Cicerón, sino que se mantiene hasta bien entrada la Edad Moderna.

La complicación consiste en que aparentemente concordia y consenso están ligadas; en cuyo caso habría que preguntarse también en qué relación está la concordia política con la ley natural, problema teóricamente más interesante.

\section{El concepto de consenso}

Santo Tomás de Aquino se ubica en el centro de la tradición clásica. Sus análisis precisos sirven para disipar las confusiones y ambigüedades gnósticas. Él analiza este concepto en la Suma Teológica I-II, q.15 ${ }^{12}$. Para

12 Santiago Ramírez hace un análisis preciso y exhaustivo de la quaestio en (1972). De actibus humanis - In I. II Summae Theologiae Divi Thomae Expositio (QQ. VI-XXI). Madrid. CSIC, 365-381. 
abreviar, digamos que el consenso se puede entender en un sentido general, en un sentido estricto y en un sentido lato.

En un sentido general, es el asentimiento voluntario a un enunciado práctico de la razón.

En un sentido estricto, es un acto de la voluntad vinculado con la deliberación y la elección; en tanto tal, es acto de voluntad sobre los medios. En la estructura del acto humano, para Santo Tomás, está en primer lugar el apetito del bien y la intención del fin, después viene la elección, y finalmente el imperio y la ejecución. El consenso presupone la intención del fin y tiene como objeto los medios para alcanzarlo. Así entendido, aparece claramente vinculado con la libertad. Así como la libertad tiene una cierta ambivalencia, porque es razón y voluntad a la vez, de la misma manera el consenso no puede ser desvinculado de la deliberación, porque presupone esta deliberación y es un asentimiento al resultado de ella; es una aceptación de los bienes que se presentan como medios para la elección.

En sentido lato, el consenso puede ser entendido como asentimiento compartido con otros; en este caso presupone necesariamente la comunicación y la deliberación intersubjetiva.

En todos los casos resulta claro que el consenso no es nunca un acto inmediato. Carece de la inmediatez que puede tener el simple querer del bien y los principios. Es siempre un acto mediado por otras operaciones; es un acto que racionalmente, ya sea como acto de conocimiento, ya sea como acto de voluntad fundada en el conocimiento, presupone un discurso, el movimiento discursivo de la razón. Es propio del querer y el conocimiento de los medios.

\section{Consenso y concordia}

Si comparamos lo dicho con la concordia, la primera dificultad es idiomática. No discuto si ha sido buena o no la traducción que hizo Cicerón de la palabra griega homónoia que usa Aristóteles. Pero el hecho es que la palabra latina concordia implica cierta ambigüedad, como se verifica incluso en Santo Tomás de Aquino. El Aquinate trata la concordia principalmente en dos partes: en el Comentario a la Ética Nicomáquea, en el cual se aproxima notablemente al sentido aristotélico de la noción; y en la Suma Teológica, en el tratado de la caridad, donde la concordia aparece como algo más general, como una unión de voluntades en torno de bienes en general. En la Ética la concordia es tratada en el Libro IX. Allí Aristóteles usa una palabra, homónoia, que podría entenderse o traducirse como sentimiento común o espíritu en común. Aristóteles cuida mucho de aclarar que este sentido de acuerdo no es propio de esta palabra, porque para hablar de un acuerdo de opiniones 
o de un acuerdo de sentimientos se podría hablar de homódoxia. Homónoia es para Aristóteles una convergencia objetiva de voluntades en torno de cosas -jrémata- que podemos traducir por intereses o cosas necesarias para la vida. ¿Qué son estas cosas que son queridas como necesarias para la vida? Son aquellas cosas importantes que el hombre quiere naturalmente, que corresponden a un apetito humano natural. Son las cosas que Santo Tomás enumera, por ejemplo, en la q. 94, cuando habla de la ley natural; cosas que operan como fines naturales.

Aquí comparece todo el universo riquísimo doctrinal de Aristóteles en torno de los fines de la vida humana, tanto de la vida humana individual como social. Estos jrémata que son necesarios para la vida fundan la convivencia, de tal manera que la vida social y política es efecto de esta voluntad humana en torno de esas cosas comunes. Por esto, la palabra homónoia más que como concordia habría que traducirla como concordia política, porque no se trata de una convergencia objetiva de dos o más voluntades privadas, sino de una convergencia objetiva, sin contratos ni acuerdos recíprocos, en la línea de los fines naturales del hombre que se realizan socialmente.

Si comparamos la concordia con el consenso, las diferencias son evidentes. Mientras el consenso tiene por objeto medios, la homónoia es en torno de fines naturales; mientras el consenso supone reflexión raciocinante, es decir, deliberación, la homónoia tiene la inmediatez propia de los principios, del primer querer, de la sindéresis. Es inmediata y por lo tanto espontánea, no es intersubjetiva, la convergencia es objetiva, es natural como es natural la vida política, como es natural el Estado, como es natural en general la vida social, ya sea en el intercambio, en el matrimonio, etc. De modo que salta a la vista la diferencia conceptual entre la homónoia o concordia política y el consenso.

\section{Concordia, consenso y ley natural}

Volvamos a la pregunta: ¿en qué relación están el consenso y la concordia, con la ley natural? De acuerdo con lo dicho, las cosas resultan relativamente claras. La concordia y la ley natural están en una misma esfera, propia de los fines. Todos los enunciados de la ley natural son finalistas; en otras palabras, la ley natural es un orden racional a fines naturales, y eso es lo que dice Santo Tomás. Las tendencias naturales de las que habla en la q. 94 (2.2, resp., segunda parte) son, precisamente, expresiones de las tendencias a fines; la ley natural expresa un orden natural de fines, ya sea en abstracto, como cuando dice "debe hacerse el bien y evitarse el mal", o cuando dice "debe obrarse de acuerdo con la razón", o ya cuando está dirigido a proteger la vida, la propiedad, el uso de los bienes materiales, etc. Y 
la concordia política es, a su vez, la convergencia objetiva de las voluntades en torno de intereses comunes inmediatamente necesarios para todos. De tal manera, lo que la ley natural ordena es, básicamente, lo que la concordia apetece. El objeto de la concordia política aparece constitutivamente vinculado con la ley natural; no podría haber ley natural si no hubiera esta homónoia política, que aparece expresada racionalmente por la ley natural. De modo que queda clara la relación de la concordia política con la ley natural, no sólo por su objeto sino también por la necesaria compenetración de voluntad e inteligencia.

¿Y en qué relación está el consenso con la ley natural? El consenso versa sobre los medios y la ley natural sobre los fines, por lo tanto, no puede pensarse nunca que el consenso sea fundamento de validez o de verdad de la ley natural, como no puede pensarse que el consenso sea, en principio, fuente de validez de un conocimiento o de la verdad. Pero sí encontramos, a la inversa, que la ley natural es medida de la validez del consenso, es decir, es regla de la rectitud de éste. No todo consenso es recto. La ley natural es regla remota de la rectitud del consenso, porque el consenso está, en relación con la ley natural, en una proporción semejante a como el medio está en relación con el fin, y así como el medio es valioso o bueno en tanto guarda una aptitud con relación al fin, de la misma manera el consenso será valioso y será recto en tanto esté ordenado al fin natural, lo cual significa que esté ajustado a la ley natural.

\section{El Derecho y los "Derechos Humanos"}

\section{Un concepto ambiguo y sospechoso}

Las expresiones "derechos del hombre", "Derechos Humanos", "derechos de la persona", "derechos fundamentales", y otras semejantes, están firmemente instaladas en las instituciones occidentales y tienen, en nuestros días, al menos para anchos sectores del pensamiento jurídico y político, un prestigio innegable. Para algunos, incluso, constituyen una expresión válida del Derecho Natural.

Sin embargo, cuando se intenta una conceptualización rigurosa y la precisa enumeración de sus propiedades, se advierten ambigüedades y, lo que es más preocupante, connotaciones políticas, antropológicas y, en definitiva, ideológicas, que convierten a todo el argumento en una tesis dialéctica cuya validez lógica y jurídica debe examinarse.

La primera razón que justifica una cierta desconfianza intelectual es el pleonasmo semántico: "derecho humano". Pues todo derecho es humano. Hablar de "derecho humano" significa una reduplicación. Entonces, la pre- 
gunta es: ¿qué se quiere decir con la reduplicación? Porque la reduplicación en sí misma no es suficientemente denotativa de nada.

Otra razón que justifica la desconfianza son sus orígenes iluministas, con una connotación histórica contraria a la tradición cristiana.

En tercer lugar, debe señalarse el abstractismo de sus formulaciones. En general, el abstractismo es siempre peligroso si no hay un control riguroso del proceso lógico de concreción de un enunciado. En este caso hay un abstractismo originario. Las expresiones que consideramos nacen como formulaciones abstractas, más propias de una ley (que es un enunciado general) que del Derecho, que no es un enunciado sino una cosa concreta. La ley misma requiere de un proceso de concreción para que sea regla eficaz de la conducta.

En cuarto lugar, hay que apuntar la utilización política selectiva de la invocación de estos Derechos Humanos. Últimamente, por ejemplo, se los ha usado para intentar legitimar el rechazo al orden natural familiar, fundado en la diversidad de sexos y en las propiedades del matrimonio.

Por último, y no es la objeción menor, hay algunos contrastes trágicos en nuestra experiencia jurídica contemporánea. Nunca se ha hablado tanto de los Derechos Humanos y de la defensa de la dignidad humana, y nunca se ha visto, como en estas últimas décadas, planes de exterminio de vida humana, como el que estamos viendo a escala mundial. Por ejemplo, hoy, millones de hombres son asesinados mediante el aborto y la eutanasia sin ningún clamor universal unánime por los Derechos Humanos. Por el contrario, muchos defensores de esta idea aceptan y justifican tales prácticas homicidas.

Cabe preguntarse: ¿cómo es posible que un teórico de los Derechos Humanos admita la violación flagrante de la vida humana? La respuesta es interesante. Se dice, "en el caso del aborto, lo que está en discusión es que haya vida humana", porque la palabra "humana" tiene sólo significación en el discurso convencional. $\mathrm{Si}$, por ejemplo, se restringe la significación convencional de "humano" a algo que tiene conciencia, un feto, e incluso un recién nacido, no es un hombre; esto vale también para el enfermo que ha perdido el uso de la conciencia.

Hay, pues, una ambigüedad semántica en la palabra "humano" que sólo podría superarse por el consenso. Lo cual de suyo es absurdo, porque las cosas son lo que son, independientemente de ningún consenso. Por otra parte, el aludido consenso no es sociológicamente real, sino sólo una opinión dominante impuesta por medios diversos. Y de este modo, puede haber "consenso" para matar hombres.

Esta ambigüedad no es una cuestión secundaria ni accidental. Se trata de una cuestión que está en la base misma de todo discurso y de toda argumentación sobre el asunto. Su alcance es inmenso. Afecta a la concepción 
acerca del hombre, al concepto mismo de Derecho, al ámbito de validez y vigencia de la ley y al valor de todo el orden jurídico.

La raíz de esta ambigüedad es el nominalismo, el voluntarismo -que deviene en convencionalismo autoritario en las fuentes de significación de términos, enunciados y normas-, y su consecuencia necesaria es el positivismo. Se trata de una cuestión metafísica que compromete a todo el pensamiento. Si no cabe hablar de una naturaleza específica real, todo discurso jurídico acerca del hombre y de lo humano carece de fundamento. El Derecho, entonces, deja de ser una cosa real. Y, como es obvio, también carece de sentido hablar de Derecho natural y de ley natural.

\section{Ambigüedad del concepto de "Derecho"}

Pero hay también una ambigüedad semántica y conceptual respecto del Derecho, que exige una especial precisión y discernimiento de las diversas acepciones de la palabra Derecho y de sus conceptos y definiciones respectivas. La palabra y el concepto de Derecho son signos lógicamente análogos ya en sus remotos orígenes clásicos. Y esa analogía debe ser tenida en cuenta cuando se pretende descifrar la significación de la expresión Derechos del hombre.

Se advierte, además, una oscilación conceptual entre "principios" y "Derecho Positivo"; una oscilación entre principios y positivización de los principios, a partir de la distinción que comienza con Esser y sigue con Dworkin, Henke, Larenz, entre otros, entre la palabra principios y normas o principios y reglas. Los Derechos Humanos a veces aparecen como derechos, pero otras veces aparecen como principios, de hecho, como principios fundamentales, pero dentro de esa laxitud que tiene el principio -para estos autores- en comparación con la regla o norma jurídica. Con lo cual los Derechos Humanos, en esta concepción, oscilan permanentemente entre cierto carácter de principios generales a partir de los cuales incluso aparece la posibilidad de conflicto de principios, y después la positivización de esos Derechos Humanos, por lo general, a través de las cortes de Derechos Humanos, cortes constitucionales, etc.

\section{3. "Derechos Humanos", bien común y aspiraciones difusas}

Desde una perspectiva gnóstica, en la que las palabras y los conceptos no tienen correlato ni fundamento en la naturaleza del hombre y de las cosas, la apelación a los "Derechos Humanos" suele confundirse con las 
aspiraciones difusas impuestas por la ideología dominante, asimiladas al contenido del bien común.

Pero el verdadero bien común político es el objeto inmediato de la justicia legal. Su ámbito excede lo jurídico porque abarca todo el campo moral, político y económico. Aristóteles lo define como la perfección de la vida social. Es el fin del Derecho y de la ley, pero no es lo suyo de cada uno, sino el fin a alcanzar en común y del que cada uno participa en una medida determinada.

El bien común no es otra cosa que un aspecto de la entelequia humana, que es el bien inmanente del hombre. El bien del hombre no es un derecho humano sino su fin. Si se confunde el bien común y la entelequia humana con los Derechos Humanos se comete un error muy grande, que tiende a confundir la política con el Derecho y a desdibujar la objetividad y la estricta medida que caracterizan a éste. La del bien común es una esfera mucho más amplia que la del Derecho. Los Derechos Humanos, en un sentido objetivo y realista, son un aspecto particular de ese bien incluido dentro de la perfección total de la entelequia humana. Pero en la perspectiva gnóstica, dado que no se admite ninguna naturaleza específica, las aspiraciones que pretenden que valgan como bien común son meramente ideológicas.

\section{Una breve conclusión}

Tres ideas expresan las condiciones en las que se podría aceptar hablar de "Derechos Humanos". Ellas son:

a) La realidad de la naturaleza específica humana, como fuente de la ley natural.

b) La objetividad estricta propia del Derecho.

c) Dios, como fundamento absoluto y trascendente del Derecho.

La realidad de la naturaleza específica del hombre, contra lo que afirma el gnosticismo y el nominalismo, es condición necesaria para el reconocimiento de Derechos Humanos que tengan un fundamento real. Es decir, un fundamento de verdad práctica.

La objetividad estricta es requisito para que hablemos propiamente de Derecho y no de un ámbito difuso en el que pueda confundirse la moral, la política y los intereses ideológicos.

Dios, fuente trascendente de toda razón y justicia, es la clave de bóveda de toda validez y vigencia jurídica y política. $\mathrm{O}$, dicho con palabras de Pla- 
tón: "No es el hombre sino Dios la medida de todas las cosas"13. Esta es la respuesta definitiva a todo gnosticismo.

\section{La "dignidad humana" como tópico gnóstico}

\section{Ambigüedad tópica}

Típicamente gnóstica es la amplificación retórica de este tópico, vinculada con las concepciones liberales, humanistas y las llamadas corrientes personalistas. Como figuras paradigmáticas cabe citar a Kant y, dentro del campo católico, a Rosmini. La idea es que el hombre, la persona humana, es un fin para sí mismo ${ }^{14}$.

Hay aquí un equívoco posible que resulta de la falta de distinción entre el orden ontológico y el orden axionormativo. Supuesto que el concepto de dignidad significa un cierto rango de bondad, dos enunciados verdaderos pueden parecer contrarios:

a) "La persona es lo más perfecto en la naturaleza"15. Esto vale también para el Demonio. Dignidad (ontológica) de la que no puede decaer.

b) El Demonio tiene máxima indignidad (moral).

Ahora bien, si el concepto de dignidad no fuera análogo, no se sería posible evitar la contradicción entre esos dos enunciados.

\section{Orden del bien}

Algo es digno porque es bueno. La dignidad es un orden de la bondad. El trascendental bonum es una propiedad del ente en cuanto éste tiene perfección. Bueno es lo perfecto y en razón de esa perfección es amable. La perfección es el fundamento objetivo de la amabilidad de algo. A su vez, perfecto, según Aristóteles, es lo que es íntegro, lo que no defecciona en ninguna de sus partes. En segundo lugar, "perfecto" es lo acabado o totalmente actualizado según su propia forma o esencia, es decir, lo máximamente excelente en su género. En tercer lugar, "perfecto" se dice de lo que ha alcanzado su fin.

13 Platón. Las Leyes, IV, 716 c4-6.

14 Cfr. Mi ponencia (2014). “¿Es la persona un fin para sí mismo?”. Actas del Primer Congreso de Filosofía Tomista. Santiago. CET, 81-95.

15 Cfr. S. Tomás. Suma Teológica, I q.29, a.3, resp. 
El esfuerzo analítico aristotélico parte de la identidad o proximidad semántica entre perfección y totalidad como un momento de la experiencia del ente finito y se resuelve en la noción de acto, entelequia.

Santo Tomás de Aquino alcanza, por su parte, una formulación más límpida y de mayor generalidad: perfectum autem dicitur, cui nihil deest secundum modum suae perfectionis ${ }^{16}$ (perfecto es aquello que no le falta nada, que no decae en nada de lo que le corresponde según su modo de perfección). El Aquinate, comentando a Aristóteles, formula una distinción de lo perfecto que será de la máxima importancia respecto del concepto de bien. Distingue lo perfecto en sí mismo, secundum se, de lo perfecto con relación a otro, respectum ad aliud. Lo perfecto secundum se se divide en:

$\left.1^{\circ}\right)$ lo que es universalmente perfecto, es decir, aquello máximamente perfecto sin que nada, absolutamente hablando, pueda superarlo en excelencia. Esto solo le corresponde a Dios;

$\left.2^{\circ}\right)$ lo que es perfecto respecto a un género de cosas determinado, es decir, aquello que no admite en su género u orden nada más excelente, aunque sí lo pueda haber en otro género u orden. Por ejemplo, en el orden de las sustancias materiales nada hay más excelente que el hombre.

Se tienen así delineados, en forma esquemática, los principales elementos nocionales del bien. Algo es bueno en tanto es perfecto, es decir, en cuanto está en acto, y la plenitud del estar en acto consiste, en definitiva, en la realización perfecta o acabada de la forma. En esto consiste la bondad a secas (bonum simpliciter loquendo). Pero también es en cierto modo bueno (secundum quid) por el hecho de existir.

Se acaban de señalar dos grupos nocionales, una bondad que no es completa, secundum quid, la bondad entitativa de la sustancia, que es real por su acto de ser, pero que todavía no alcanzó su última perfección; a esto lo vamos a denominar bondad ontológica radical. En segundo lugar, la bondad propiamente dicha, simpliciter loquendo, aquello que ha alcanzado su fin, su perfección última, y a esto corresponde, en el caso del hombre, la perfección moral.

\section{La dignidad como orden del bien}

Lo que es bueno en sí mismo, bonum, perfectum secundun se, lo es por orden al fin, pues lo bueno en sí mismo es fin. Lo bueno en relación a otro es

16 Santo Tomás de Aquino. Suma Teológica, I q. 5 a. 5, resp. 
medio en tanto toda su bondad derive de su ordenación a lo bueno en sí. Lo dicho debe aplicarse al tema de la dignidad.

"Dignidad" significa la bondad de algo en razón de sí mismo, es decir, secundum se, o propter se ipsum. La dignidad es el máximo valor relativo de algo que es bueno secundum se, es decir, estamos hablando de algo que es fin. Es claro entonces que el orden de la dignidad sigue al orden del bien. Y, así como el bien y el ente se dicen de muchas maneras (se predican con analogía de cosas esencialmente distintas), así también el concepto de dignidad. El concepto de dignidad solo agrega al concepto de bueno una referencia a un orden, jerarquía o grado. Por lo tanto, la radical analogía del concepto trascendental de bonum vale también para el concepto de dignidad. Habrá, pues, dignidades ontológicas, epistemológicas, morales, etc., y conviene no confundirlas.

Pongamos un ejemplo. La dignidad ontológica de un santo y la de un rufián es la misma; y la de un demonio es superior a la de todo hombre. Y merece un respeto especial pese a la indignidad moral en la que haya incurrido. Tómese por ejemplo el siguiente pasaje de la Epístola de San Judas, versículo 9: "El Arcángel Miguel, cuando altercaba con el Diablo contendiendo sobre el cuerpo de Moisés, no se atrevió a proferir un juicio injurioso, sino que dijo: 'que el Señor te reprenda"'. Es de notar que, por una parte, le reconocía la dignidad ontológica, en razón del grado de perfección que tenía por su naturaleza. Pero por otro lado, prevaleció sobre él para que no se hiciera su voluntad emponzoñada. En el ejemplo, como parece claro, el respeto a la dignidad ontológica que conserva el Demonio no impide a Dios encerrarlo en el Infierno.

\section{Conclusión}

La dignidad ontológica de la persona humana merece un reconocimiento congruo en el orden social, jurídico y político. En ningún caso se puede tratar a una persona humana como a una cosa o un animal. Pero a la vez, la dignidad moral -y su contrario, la indignidad- merece el propio reconocimiento que puede ser harto diferente, y puede ocurrir que un ente con máxima dignidad ontológica incurra en máxima indignidad moral.

La estrategia de la ideología gnóstica consiste en la confusión semántica y axiológica. En el orden moral, social, jurídico y político, la dignidad humana que debe ser tenida en cuenta, principalmente, es la que se funda en el bien específicamente personal, que siempre es de naturaleza moral y que está ordenado al bien común. Y la indignidad moral no puede ser perdonada o ignorada en razón de la dignidad ontológica. 


\section{Colofón}

La verdad es una sola. El error es potencialmente infinito. La ley natural es la verdad de la naturaleza de las cosas y del hombre hecha regla universal de conducta. Es la verdad de la Sabiduría Ordenadora Divina en la medida asequible a la razón humana. El gnosticismo es la antigua negación de un único Dios trascendente y creador, para cuyo conocimiento, amor y servicio fue creado el hombre. Es la negación de un fin suprahistórico de la historia, y del Reino de Dios, distinto, infinitamente superior y trascendente al reino del hombre o de cualquier otra creatura.

Las estrategias gnósticas y los instrumentos filosóficos para negar o desfigurar la ley natural son múltiples: nominalismo, empirismo, idealismo, positivismo, modernismo, progresismo, iluminismo, relativismo cultural, matematicismo, pactismo, economicismo, etc. Elegí tres instrumentos gnósticos en particular; lo hice porque ellos cumplen con eficacia la misión de enmascarar o sustituir la verdadera doctrina acerca de los principios legitimantes de los actos humanos y de sus instituciones sociales y jurídicas. Ellos, incluso, han conseguido instalarse en los círculos que pretenden el reconocimiento como iusnaturalistas. Tres tópicos que, apoyados en una parte de verdad, se alejan de ella e intentan desnaturalizarla.

Pero la verdad de la ley natural es la garantía del triunfo de la razón y la justicia.

\section{Bibliografía}

Lamas, F. A. (2014). “¿Es la persona un fin para sí mismo?”. Actas del Primer Congreso de Filosofía Tomista. Santiago. CET, 81-95.

—, Las Leyes, IV, 716 c4-6.

-, (1990). Los gnósticos (compilación). Intr., trad. y notas de José Montserrat Torrents. 2 tomos. Madrid. Gredos.

Meinvielle, J. (1994). De la cábala al progresismo. Buenos Aires. Epheta.

Ramírez, S. (1972). "De actibus humanis". In I.II Summae Theologiae Divi Thomae Expositio (QQ. VI-XXI), Madrid. CSIC, 365-381.

San Agustín de Hipona (1993). Obras completas. Tomos XXX y XXXI. Madrid. BAC, en especial el "Contra Faustum".

Santo Tomás de Aquino. Suma Teológica, I q. 29, a. 3 resp.

Santo Tomás de Aquino. Suma Teológica, I q. 5 a. 5 resp.

Voegelin, E. (2006). La nueva ciencia de la política. Una introducción. Buenos Aires. Katz, caps. IV y V. 